\title{
Recursos genéticos de espécies frutiferas nativas da Amazônia Brasileira
}

\author{
Charles R. Clement (') \\ Carlos Hans Múiler $\left({ }^{2}\right)$ \\ Wander's B. Chavez Flores (')
}

\begin{abstract}
Resumo
Este artigo reúne parte dos estudos com recursos genéticos das espécies frutiferas indigenas da Amazônia. Apresentam-se listas de prioridades históricas e atuais de cada instituição que se dedica à pesquisa com estas espécies, as listas das coleçōes e os bancos de germoplasma de cada instituição e suas possibilidades imediatas para expandir estas pesquisas. Apresentamse algumas informações sobre diversas espécies prioritárias, comentários sobre o respectivo potencial econômico e algumas consideraçōes sobre a ameaça de erosão genética que cada uma enfrenta. Discute-se a situação atual da prospecção e conservação de germoplasma de espécies frutiferas nativas da região Amazônica e apresentam-se sugestōes para conservação destes recursos genéticos.
\end{abstract}

\section{INTRODUÇÃ̃o}

A região Amazônica possui valioso repositório de recursos genéticos de espécies frutíferas (Calzavara, 1978) e as diversas listas elaboradas mencionam centenas de espécies com diferentes níveis de importância na região (Hoehne, 1946; Le Cointe, 1947; Correa, 1926/ 69; Cavalcante, 1976 e 1979). Entretanto, a maioria destas espécies ainda é pouco conhecida quanto ao potencial de exploração econômica e sua contribuição para o bem-estar humano na região, assim como na economia nacional,

Nas estimativas sobre a riqueza florística da região, freqüentemente mencionam-se de 50 a 60 mil espécies de plantas superiores (Myers, 1979; Schultes, 1977), porém, a região tem contribuído com poucas espécies para culturas econômicas. Entretanto, algumas espécies amazônicas alcançaram posição destacada na agricultura tropical do mundo, como por exemplo, o cacau (Theobroma cacao Linn.), a seringueira (Hevea spp.) e o abacaxi (Ananas comosus Merril). Outras são economicamenta impcrtantes apenas na região, como a castanhado-Brasil (Bertholletia excelsa H.B.K.) e o guaraná (Paullinia cupana H.B.K.). A lista de espécies frutiferas da flora Amazônica que têm contribuído para o desenvolvimento da região pode ser ampliada por meio da avaliação de outras espécies popularmente usadas, seguirido-se o exemplo do que vem sendo feito em outras regiões dos trópicos úmidos, como na Ásia e América Central.

O rítmo acelerado da colonização e do de. senvolvimento de grandes projetos na região Amazônica, está ameaçando esta riqueza florística e principalmente as espécies frutíferas. Estes projetos ameaçam diretamente as populações de fruteiras em diferentes locais, porém a colonização ameaça mais seriamente dada a migração de pessoas com hábitos alimentares distintos as quais desprezam as frutas regionais, que estão desaparecendo das feiras. A emeaça de perda de algumas espé. cies (Lovejcy, 1979; Myers, 1979) e, assim como também da diversidade genética (Frankel, 1977; Clement \& Arkcoll, 1980), seguramente limitará a contribuição das mesmas ac desenvolvimento sócio-econômico da região com novas opções de cultivos perenes para os trópicos úmidos.

A Amazônia constitui a última fronteira agrícola de grande extensão no mundo, porém apresenta uma série de condições ecológicas especiais que precisam ser conhecidas e adequadamente manejadas para que a região possa ser largamente explorada. Numa reunião realizada em abril-1980, no C!AT-Colômbia, fo! elaborado um documento sobre uma estratégia

(1) - Instituto Nacional de Pesquisas da Amazônia. Manaus.

(2) - Centro de Pesquisas Agropecuárias do Trópico Úmido - CPATU/EMBRAPA, Belém, PA. 
para a transferência de pesquisa e tecnologia para melhorar a utilizaçãu dos recursos da região Amazônica. Aquele documento reconhece a necessidade urgente de pesquisas básicas sobre o ecossistema regional, e, também, destaca como pricridade a coleção, avaliação e distribuição de recursos genéticos regionais.

Neste trabalho, pretende-se divulgar o que vem sendo feito com os recursos genéticos frutícolas na Amazônia Brasileira. Nas últimas cinco décadas, diversas instituições têm atuado na região, dando ênfase a diferentes espécies, porém a continuidade necessária para trabalhar com cultivos perenes tem sido marcada mais por sua ausência de que por sua presença. Felizmente, tudo leva a crer que é chegado o momento de as entidades de pesquisa nacional tomarem consciência da importância de estudos mais aprofundados quanto aos recursos genéticos de espécies frutíferas da Amazônia, bem como da coleta, avaliação e a conservação destes recursos. Com a criação do Centro Nacional de Recursos Genéticos, CENARGEN / EMBRAPA em 1974, e a subseqüente elaboração do Programa Nacional d€ Pesquisas de Recursos Genéticos, a conscientização da importância dos recursos genéticos foi institucionalizado. Nos últimos anos, o CENARGEN vemi ampliando a atenção de seu Programa na região Norte, primeiro para buscar germoplasma de abacaxi para o Centro Nacional de Pesquisas de Mandioca e Fruticultura, CNPMF. As espécies forrageiras têm merecido atenção e ultimamente o caiaué (Elaeis oleifera (H.B.K.) Cortes) e seringueira com o Centro Nacional de Pesquisas de Seringueira e Dendê, CNPSD; guaranả com Unidade de Execução de Pesquisas no Ambiente Estadual do Amazonas, UEPAE-AM; castanha-do-Brasil com - Centro de Pesquisas Agropecuárias do Trópico Úmido, CPATU e UEPAE-Acre; pupunha (Bactris gasipaes H.B.K.) com o Instituto Nacional de Pesquisas da Amazônia, INPA e babaçu (Orbignya martiana Barb. Rodg.) com o Instituto Estadual de Babaçu, INEB (Maranhão) e a Empresa Maranhense de Pesquisas Agropecuária, EMAPA. A amplıação dos interesses deste Centro em conjunto com as demais instituições da Amazônia Brasileira, é uma causa para otimismo. No entanto, ainda é pouca coi. sa e o tempo está correndo.
INSTITUiçõEs : AS COLFÇÕES DE FRUTEIRAS AMAZONNICAS QUE FOSSUEM
1. Centro de Pesquisas Agropecuárias do Trópico Úmido - CPATU-EMBRAPA (Be- lém, PA)

O CPATU é a primeira das instituições regionais, historicamente e em termos de área ativa. As atividades constam de coleta, introdução, avaliação, multiplicação e distribuição de germoplasma de fruteiras indígenas. O Centro foi fundado em 1939 conhecido então como Instituto Agronômico do Norte, IAN. Em 1962 passou a Instituto de Pesquisa e Experimentação Agropecuária do Norte, IPEAN (Albuquerque \& Libonati, 1964). Nesta fase, o Instituto executou projetos de pesquisa com cacau. castanhado-Brasil, cumaru (Dipteryx odorata (Aubl.) Willd.), dendê (Elaeis guinensis Jacq.), caiaué, cupuaçu (Theobroma grandiflorum (Willd. ex Spreng.) Schum.), bacuri (Platonia insignis Mart.), murici (Byrsonima crassifolia (L.) Kunth), açai-do-Pará (Euterpe oleracea Mart.), pupunha, bacaba (Oenocarplis bacaba Mart.), tucumã (Astrocaryum tucuma Mart.), guaraná, urucu (Bixa orellana L.), sorva (Couma utilis Mart.) M. Arg.) e outras. Foram instaladas várias coleções e plantações extensas de germoplasma coletados nas mais diversas áreas da Amazônia. Infelizmente, os trabalhos so. freram uma certa paralização no início da implantação da EMBRAPA quando se perderam muitos acessos.

Com a criação do CPATU, em 1976, novas prioridades foram definidas $e$ as pesquisas se concentraram em guaraná, castanha-do-Brasil, dendê e caiaué, porém a coleta de germoplas. ma das demais espécies frutíferas não foi considerada até o presente. Apesar de a direção da EMBRAPA reconhecer a importância das culturas frutíferas perenes para o desenvolvimenio agrícola da Amazônia, não conseguiu ainda estabelecer um Programa Nacional de Pesquisa de Espécies Frutíferas da Amazônia As pesquisas atuais com espécies frutíferas locais näo levam em conta a variabilidade genética do material coletado, o que restringe consideravelmente a possibilidade de seleção de cultivares mais produtivos com características melhoradas e até mesmo com resistência a condições adversas do meio, às doenças e pragas. 
A Tabela I mostra as espécies indígenas da Amazônia com ampla ocorrência na região, as quais o CPATU mantém atualmente. Notase que a espécie com maior número de acessos é a castanha-do-Brasil, que constitui o principal projeto com fruteiras do CPATU. Os estudos tém resolvido diversos problemas sobre a domesticação desta espécie e a coleção contém acessos com alto rendimento e excepcional qualidade de amêndoa. Vale mencionar que estes acessos são mantidos na forma de clones selecionadcs no campo e enxertados não existindo progenie das matrizes selecionadas.

A coleção de sapota do CPATU é uma repetição da do INPA, contendo 12 clones selecionados, que estão sendo avaliados para doterminar-se adaptabilidade aos solos e clima de Belém. Todo o resto da coleção é composto de um só acesso por espécie o que reflete o objetivo do projeto, que busca determinar espécies frutiferas próprias para consórcio $\mathrm{com}$ pasto. E evidente que, com à exceção do trabalho com a castanha-do-Brasil, a orientaçãc deste Centro é limitada a testar a adaptabili. dade de espécies, sem levar em conta a conservação e exploração da variabilidade genética.

\section{Faculdade de Ciências Agrárias do Pará - FCAP (Belém, PA)}

A FCAP, fundada em 1950, então Escola de Agronomia da Amazônia, só passou a receber a atual denominação em 1972. Apesar de uma ligação com CPATU, a FCAP só iniciou um programa de pesquisas próprias ria área de fruticultura em 1975, com o apoio financeiro da SUDAM. Seu campo experimental se localiza em Benfica, PA. Este programa conduz pesqui-

TABELA 1 - Espécies frutiferas amazônicas, reprosentadas nas coleçōes do CPATU-EMBRAPA.

\begin{tabular}{|c|c|c|c|}
\hline Nome Vulgar & Nome Cientifico & Familia & $\begin{array}{l}\mathrm{N} \cdot{ }^{\circ} \text { de } \\
\text { Acessos }\end{array}$ \\
\hline 1. Taperebá & Spondias lutea L. & Anacardiaceae & 1 \\
\hline 2. Araticum & Annona montana Macf. & Anonaceae & 1 \\
\hline 3. Graviola & Annona muricata $\mathrm{L}$. & $n$ & 1 \\
\hline 4. Bíribá & Rollinia mucosa (Jacq.) Baiil. & " & 1 \\
\hline 5. Sorva & Couma macrocarpa Barb. Rodr. & Apocinaceae & 1 \\
\hline 6. Mangaba & Hancornia speciosa Gom. & $n$ & 1 \\
\hline 7. Sapota & Quararibea cordata (Humb. \& Bonpl.) Vischer & Bombacaceae & 13 \\
\hline 8. Bacuri & Platonia insignis Mart. & Gutiferae & $i$ \\
\hline 9. Bacuri-pari & Rheedia macrophylla (Mart.) PI. et Tr. & $n$ & 1 \\
\hline 10. Castanha-do-brasil & Bertholletia excelsa H.B.K. & Lecitidaceae & 45 \\
\hline 11. Ingá & Inga edulis Mart. & Leg. Mimosoidea & 1 \\
\hline 12. Ciruela & Bunchosia armeniaca (Cav.) Rich. & Malpiguiaceae & 1 \\
\hline 13. Muruci & Byrsonima crassifolia (L.) Kunth & " & 1 \\
\hline 14. Mapati & Pourouma cecropiaefolia Mart. & Moraceae & 1 \\
\hline 15. Ameixa & Eugenia cumini (L.) Druce & Myrtaceae & 1 \\
\hline 16. Araçá-boi & Eugenia stipitata McVaugh & " & 1 \\
\hline 17. Ginja & Eugenia uniflora $\mathrm{L}$. & $"$ & 1 \\
\hline 18. Grumixama & Eugenia brasiliensis Lam. & $n$ & 1 \\
\hline 19. Goiaba & Psidium guayava L. & $"$ & 1 \\
\hline 20. Guaburaba & Campomanesia lineatifolia Ruiz \& Pav. & $n$ & 1 \\
\hline 21. Pupunha & Bactris gasipaes H.B.K. & Palmae & 1 \\
\hline 22. Marajá & Bactris maraja Mart. & $"$ & 1 \\
\hline 23. Açaí & Euterpe olerácea Mart. & $"$ & 1 \\
\hline 24. Bacabinha & Oenocarpus minor Mart. & ” & 1 \\
\hline 25. Bacaba-de-leque & Oenocarpus distichus Mart. & $n$ & 1 \\
\hline 26. Pitomba & Melicocca bijuga L. & Sapindaceae & 1 \\
\hline 27. Abiu & Pouteria caimito (Ruiz \& Pav.) Radlk. & Sapotaceae & 1 \\
\hline 28. Cupuaçu-do-Amapá & Theobroma canumanenses Pires et. Fróes & Sterculiaceae & 1 \\
\hline 29. Cupuaçu & Theobroma grandiflorum (Wild. ex Spreng) Schum. & $n$ & 1 \\
\hline
\end{tabular}


sa com pouca atenção aos aspectos de recursos genéticos, apesar de reconhecer a validade de testar diversos acessos. Espera-se muito deste programa, pois é o mais abrangente trabalho na Amazônia Oriental.

$\mathrm{Na}$ Tabela 2, observam-se as espécies com as quais a FCAP trabalha. Nesta coleção, com exceção da goiaba (Psidium guayava L.), o registro de germoplasma não indica a procedência do material introduzido. O programa da FCAP inclui, além da avaliação e seleção, estudo's básicos sobre a domesticação das espécies consideradas. Este programa conta com apoio financeiro da SUDAM. O registre cuidadoso das introduções, incluindo procedência contribuira para melhorar o programa da ,FCAP cuja coleçăo é a maior da Amazônia Oriental.

\section{Instituto Nacional de Pesquisas da Ama- zônia - INPA-CNPq (Manaus, AM)}

$\mathrm{Na}$ Amazônia Ocidental, as pesquisas com espécies frutíferas são mais recentes, iniciadas somente em 1975. Sob a orientação inicial do Dr. Warwick E. Kerr, que então dirigia a dita instituição, os trabalhos foram iniciados com uma ambiciosa coleção de germoplasma das espécies da Amazônia e em especial da Amazônia Ơcidental, visando-se a formar uma coleção para a conservação "ex situ" destas espécies e pará futuros trabalhos de melhora- mento. Após alguns anos; a equipe definiu as seguintes prioridades: pupunha, cupuaçu, mapati (Pourouma cecropiaefolia Mart.), araçáboi (Eugenia stipitata McVaugh), araçá-pera (Psidium acutangulum DC.), sapota (Quararibea cordata (Humb. \& Bonpl.) Vischer), camucamu (Myrciaria dubia (H.B.K.) McVaugh), graviola (Annona muricata L.), abiu (Pouteria caimito (Ruiz \& Pav.) Radlk.) e sapoti (Manilkara zapota (L.) von Royen). A continuidade destes trabalhos tem sido razoável e tende a meihorar no futuro próximo, com colaboração do CENARGEN para a' implantação do Banco Ativo de Germoplasma de Pupunha (BAG/Pupunha).

A Tabela 3 mostra as espécies colecionadas pelo INPA, nos últimos cinco anos. Destaca-se a pupunha, justamente a espécie com um maior potencial para se tornar um cultivo com expressão econômica na região, graças ao valor alimentício de seus frutos, e a possibilidade de exportação dos seus palmitos de excelentes características para o mercado internacional. A lista de prioridades está relativamente bem apresenta na Tabela 3 .

4. Unidade de Execução de Pesquisas no Ânbito Estadual - UEPAE-EMBRAPA (Manaus, $A M$ )

Desde o tempo do IAN, existia a estação experimental conhecida como o Instituto de

TABELA 2 - Espécies frutíferas amazônicas, representadas no programa de fruticultura da FCAP*.

\begin{tabular}{|c|c|c|c|}
\hline Nome Vulgar & Nome Científico & Familia & $\begin{array}{l}\mathrm{N} .^{\circ} \text { de } \\
\text { Acessos }\end{array}$ \\
\hline 1. Caju & Anacardium occidentale L. & Anacardiaceae & 2 \\
\hline 2. Graviola & Annona muricata $\mathrm{L}$. & Anonaceae & 1 \\
\hline 3. Sorva & Couma utilis (Mart.) M. Arg. & Apocinaceae & 1 \\
\hline 4. Mangaba & Hancornia speciosa Gom. & $"$ & 1 \\
\hline 5. Bacuri & Platonia insignis Mart. & Gutiferae & 1 \\
\hline 6. Muruci & Byrsonima crassifolia (L.) Kunth & Malpiguiaceae & 1 \\
\hline 7. Goiaba & Psidium guayava L. & Myrtaceae & 13 \\
\hline 8. Pupunha & Bactris gasipaes H.B.K. & Palmae & 4 \\
\hline 9. Açai-do-pará & Euterpe olerácea Mart. & $"$ & 2 \\
\hline 10. Patauá & Jessenia bataua (Mart.) Burr. & $"$ & 1 \\
\hline 11. Bacaba-de-leque & Oenocarpus distichus Mart. & $n$ & 1 \\
\hline 12. Maracujá & Passiflora edulis Sims. & Passifloraceae & 1 \\
\hline 13. Abiu & Pouteria caimito (Ruiz \& Pav.) Radlk. & Sapotaceae & 1 \\
\hline 14. Cupuaçu & Theobroma grandiflorum (Wild. ex Spreng) Schum. & Sterculiaceae & 4 \\
\hline
\end{tabular}

- Segundo o Prof. B.B.G. Calzavara, da Facuidade de Ciências Agrárias do Pará, Depto. de Fitotecnia. 
TABELA 3 - Espécies frutiferas amazônicas, representadas nas coleções de fruteiras do INPA.

\begin{tabular}{|c|c|c|c|}
\hline Nome Vulgar & Nome Científico & Familia & $\begin{array}{l}\mathrm{N} .^{\circ} \mathrm{de} \\
\text { Acessos }\end{array}$ \\
\hline 1. Caju & Anacardium occidentale L. & Anacardiaceae & 3 \\
\hline 2. Cajuí & Anacardium gigantum Hanc. ex Engler & $n$ & 1 \\
\hline 3. Cajarana & Spondias dulcis Forst. & $"$ & 1 \\
\hline 4. Araticum & Annona montana Macf. & Anonaceae & 3 \\
\hline 5. Graviola & Annona muricata L. & $"$ & 14 \\
\hline 6. Condessa & Annona glabra Linn. & ” & 1 \\
\hline 7. Biribá & Rollinia mucosa (Jacq.) Baill. & $"$ & 14 \\
\hline 8. Sorvinha & Couma utilis (Mart.) M. Arg. & Apocinaceae & 1 \\
\hline 9. Sapota & Quararibea cordata (Humb. \& Bonpl.) Vischer & Bombacaceae & 27 \\
\hline 10. Piquiá & Caryocar villosum (Aubl.) Pers. & Caryocaraceae & 2 \\
\hline 11. Pajurá & Couepia bracteosa Benth & Crisobalanaceae & 1 \\
\hline 12. Bacuri-pari & Rheedia macrophylla (Mart.) PI. et $\mathrm{Tr}$ & Gutiferae & 2 \\
\hline 13. Bacurizinho & Rheedia brasiliense PI. et Tr. & 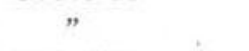 & 1 \\
\hline 14. Jatobá & Hymenaea courbaril L. & Leg. Cesal. & 1 \\
\hline 15. Ingá batelão & Inga cinnamomea Spruce ex Benth. & Leg. Mim. & 1 \\
\hline 16. Ingá curva & Inga macrophylla H.B.K. & $n$ & 1 \\
\hline 17. Muruci & Byrsonima crassifolia (L.) Kunth. & Malpiguiaceae & 1 \\
\hline 18. Cereja & Malpighia punicifolia L. & $"$ & 1 \\
\hline 19. Mapati & Pourouma cecropiaefolia Mart. & Moraceae & 32 \\
\hline 20. Grumixama & Eugenia brasiliensis Lam. & Myrtaceae & 1 \\
\hline 21. Araçá-boi & Eugenia stipitata McVaugh & $"$ & 9 \\
\hline 22. Araçá-pera & Psidium acutangulum DC. & $”$ & 7 \\
\hline 23. Goiaba & Psidium guayava L. & $n$ & 3 \\
\hline 24. Araçá & Psidium guianensis Swart. & $"$ & 3 \\
\hline 25. Camu-camu & Myrciaria dubia (H.B.K.) McVaugh & $"$ & 4 \\
\hline 26. Pupunha & Bactris gasipaes H.B.K. & Palmae & 283 \\
\hline 27. Açaí-do-pará & Euterpe oleracea Mart. & $"$ & 2 \\
\hline 28. Puruí & Borojoa duckii Steyerm. & Rubiaceae & 2 \\
\hline 29. Guaraná & Paullinia cupana H.B.K. & Sapindaceae & 1 \\
\hline 30. Pitomba & Talisia esculenta Radlk. & $"$ & 3 \\
\hline 31. Lucuma & Lucuma obvata H.B.K. & Sapotaceae & 1 \\
\hline 32. Sapoti & Manilkara zapota (L.) von Royen & 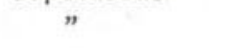 & 5 \\
\hline 33. Abiu & Pouteria caimito (Ruiz \& Pav.) Radlk. & $"$ & 24 \\
\hline 34. Pariri & Pouteria pariry (Ducke) Baehni & " & 1 \\
\hline 35. Cacau-do-Peru & Theobroma bicolor Humb. \& Bonpl. & Sterculiaceae & 1 \\
\hline 36. Cupuaçu & Theobroma grandiflorum (Wild. ex Spreng) Schum. & $n$ & 4 \\
\hline
\end{tabular}

Pesquisá e Experimentação Agropecuária da Amazônia Ocidental, IPEAOC e o qual, com a criação da EMBRAPA, foi transformado em uma Unidade de Execução de Pesquisa de Âmbito Estadual, UEPAE. Esta UEPAE conta com uma estação experimental no centro da cultura do guaraná em Maués, onde existe uma coleção de germoplasma deste cultivo. A UEPAE é hoje coordenadora do programa de guaraná da EMBRAFA e tem como prioridade a coleção, caracterização, avaliação e conservação de recursos genéticos de guaraná. Existem três áreas do Banco Ativo de Germoplasma de Guaraná: Manaus, Maués e Belém.

$\mathrm{Na}$ Tabela 4, observa-se que o BAG-Guaraná está em pleno funcionamento com muitos acessos. As pesquisas da UEPAE incluem meIhoramento, especialmente para aumento de rendimento. A média anual de produção por planta no Estado do Amazonas gira em torno de 250 gramas, enquanto que a UEPAE tem seleções que alcançam até $9 \mathrm{~kg}$. A UEPAE coletará num futuro próximo espécies silvestres de Paullinia e está expandindo a coleta de Paullinia cupana var. cupana. 
TABELA 4-O guaraná (Paullinia cupana var. sorbilis, Sapindaceae) no BAG-Guaraná sob a coordenação da UEPAE-EMBRAPA (Manaus, AM)".

\begin{tabular}{lc}
\hline \multicolumn{1}{c}{ Localização } & $\begin{array}{c}\text { N. de } \\
\text { Acessos }\end{array}$ \\
\hline $\begin{array}{l}\text { UEPAE-EMBRAPA, Km } 30 \text { AM-010, } \\
\text { Manaus, AM }\end{array}$ & 86 \\
$\begin{array}{l}\text { Campo Experimental de Maués, } \\
\quad \text { Maués, AM }\end{array}$ & 36 \\
Cacau Pirera, AM & 08 \\
CPATU-EMBRAPA, Belém, PA & 71 \\
\hline Total & 201 \\
\hline
\end{tabular}

$(*)-$ Kato, 1980.

5. Centro Nacional de Pesquisas de Mandioca e Fruticultura - CNPMF-EMBRAPA (Cruz das Almas, BA)

Embora o CNPMF seja uma instituição extra-regional, seu interesse $\mathrm{\epsilon} m$ germoplasma de abacaxi e as excursōes de coleta que tem realizado em todo o país, inclusive na Amazônia, indicam a importância para incluí-lo aqui. $\mathrm{Na}$ Tabela 5 , observa-se que o BAG-Abacaxi está dando atenção não só ao abacaxi mas também às espécies afins. Nem todos os acessos são da Amazônia, porém sabe-se que a coleta dos recursos genéticos de Ananas spp. na Amazônia é meta prioritária deste Centro. Dentro da diversidade de Ananas já coletada - CNPMF tem encontrado resistência ao fungo Fusarium moniliforme var. subglutinas, principal doença do abacaxi no Brasil (G. Ferraz Souto, com. pess.) .

6. Comissão Executiva do Plano da Lavoura Cacaueira - CEPLAC (Itabuna, BA; Belém; Mianaus)

Outra instituição com sede extra-regional, porém com infraestrutura e pesquisa na Amazônia é a CEPLAC. Esta instituição tem trabaIhado extensivamente na prospecção genética do gênero Theobroma, com ênfase ao cacau, por isto, suas coleções são pobres em material das espéties afins (veja Tabela 6). A Theobroma grandiflorum tem mostrado certa resistência à Vassoura de Bruxa em alguns lu- gares (com. pess. B. Bartley). Suas coleções são extensas, com plantações nos três centros mencionados. Desde 1976, a coleção de recursos genéticos dè cacau tem recebido mais ên. fase. A CEPLAC instalou e coordena o BAGCacau apoiado pelo CENARGEN.

\section{Centro Nacional de Pesquisa de Seringa e Dendê - CNPSD-EMBRAPA (Manaus, AM)}

Em 1977, foi criado o CNPSe e, em 1980, as pesquisas com dendê foram transferidas do CPATU para o CNPS, criando-se o CNPSD, com sede em Manaus, Amazonas. Este Centro está iniciando uma coleção dos recursos genéticos de caiaué incorporados ao BAG-Dendê.

\section{Empresa de Pesquisas Agropecuárias do Ceará - EPACE (Fortaleza, CE)}

A EPACE iniciou o BAG-Caju (Anacardium occidentale L.), em 1975, na Unidade de Pes. quisu do Litoral em Pacajus, CE. Embora a EPACE seja uma instituição extra-regional, tem realizado coleta de germoplasma do gênero Anacardium na Amazônia. Atualmente, dispõe de uma coleção muito boa e pretende realizar mais coletas na Amazônia (Barros, 1980).

TABELA $5-0$ abacaxi e espécies afins no BAG-Abacaxi sob coordenação do CNPMF-EMBRAPA (Cruz das Almas, BA)*.

\begin{tabular}{lc}
\multicolumn{1}{c}{ Espécies } & $\begin{array}{c}\text { N. } \text { de } \\
\text { Acessos }\end{array}$ \\
\hline 1. Ananas ananassoides (Baker) L.B. Smith & 02 \\
2. A. bracteatus (Lindley) Schultes & 10 \\
3. A. comosus (L.) Merril & 109 \\
4. A. erectifolius L.B. Smith & 01 \\
5. A. lucidus (Miller) Mez. & 02 \\
6. Ananas sp. & 20 \\
7. Bromelia balansae Mez. & 01 \\
8. B. laciniosa Mart. ex Schultes & 01 \\
9. B. plumieri (E. Morr.) L.B. Smith & 01 \\
10. Bromelia sp. & 16 \\
11. Pseudoananas sagenarius Hassler ex Harns. & 05 \\
\hline (*) - Comunicaçáo pessoal, $\odot$. Ferroz Souto, CNPMF, e F. R.
\end{tabular}

Crement et al 
TABELA 6 - Acessos de cacau e espécies afins no BAG-Cacau sob a coordenação da CEPLAC*.

\begin{tabular}{l|r|r|r}
\hline \multicolumn{1}{c|}{ Espécie } & Belém, PA & Manaus, AM & Itabuna, BA \\
\hline Theobroma cacao L. & & 927 & 32 \\
T. grandiflorum (Willd. ex Spreng) Schum & & 1 & 56 \\
T. speciosum Willd. & & - & 1 \\
T. subincanum Mart. & & 1 & 1 \\
T. bicolor Humb. \& Bonpl. & & 1 & - \\
T. obovatum Klotzsch ex Bernoulli & & 2 & - \\
T. sylvestre Mart. & & 1 & - \\
Herranea sp. & & & 1 \\
\hline
\end{tabular}

(*) - As informaçốes foram fornecidas pelos Engọs Agrọs Júlio P. Barriga, CEPLAC.Belém; Dr. Basel G. Bartley, CEPLAC-ltabuna e a Engạ Agrạ Noémia N. Vasconcelos, CEPLAC-Manaus

\section{Outras instituições que estão iniciando tra- balhos nesta área}

O Dept 9 de Biologia, da Universidade Federal do Maranhão está iniciando uma coleção de germoplasma para estudar a adaptação de espécies frutiferas nativas da Amazônia às condições da região "Pré-Amazonia". A UEPAEEMBRA?A em Rio Branco, Acre, está iniciando uma duplicação da coleção de clones de castanha-do Pará mantida pelo CPATU. Futuramente, esta instituição pretende coletar material genético de castanha na Amazônia Ocidental. A Universidade Federal do Acre está implan. tande uma coleção de germoplasma de espécies frutíferas nativas com a orientação dc INPA e dentro de alguns anos deverá ter uma coleção representativa do Estado do Acre.

\section{AS FSPECIES MAIS PROMISSORAS INCLUÍDAS NAS COLEÇõES}

As coleções de espécies frutíferas da Amazônia e as avaliaçöes realizadas durante o decorrer dos anos permitem estabelecer prioridades baseadas na potencialidade destas espécies. Um exame das espécies já citadas e outras consideradas promissoras permitirão a exploração de espécies que poderão contribuir como cultivos alternativos ao desenvolvimento de uma agricultura perene que atende melḷ̂r as exigências ecológicas da região.

O cacau é a cultura mais conhecida da região Amazônica, de onde se expandiu para ou- tras regiōes de clima adequado no Brasil e no exterior. Embora originário das Américas, seu centro de origem ainda não foı possível determinar. O germoplasma de cacau é dividido em dois grandes grupos, cada um com muita variabilidade genética; estes grupos são: 1) "Criolo" da América Central e Norte da América do Sul; 2) "Amazônico" da Bacia Amazônica. O segundo grupo está sendo estudado intensivamente pela CEPLAC, que está organizando prospecções para coletar este material. As populaçõ̉es deste grupo sofrem o intenso ataque da Vassoura de Bruxa (Crinipellis perniciosa (Stahel) Singer), por isto espera-se encontrar fonte de resistência a esta doença. A ameaça de erosão deste grupo é séria em algurıs locais, o que não ocorre na maioria da regiăo porque as sementes são coletadas para o comércio e por isto, as populações são protegidas.

TABELA 7 - 0 caju e espécies afins no BAG-Caju sob coordenação da EPACE (Pacajus, CE), (Barros, 1980).

\begin{tabular}{lr}
\hline \multicolumn{1}{c}{ Espécies } & $\begin{array}{c}\mathrm{N} . \text { de } \\
\text { Acessos }\end{array}$ \\
\hline Anacardium occidentale L. & 282 \\
A. humile St. Hil. & 1 \\
A. othonianum (?) & 1 \\
A. microcarpum Ducke & 1 \\
\hline
\end{tabular}


Uma outra espécie amazônica com grande expressâo econômica é o abacaxi. Năo se sabe se o abacaxi doméstico é originário da Amazônia ou de outras áreas da América Tropical. No entanto, os recursos genéticos de Ananas com osus e espécies afins, incluindo de outros gêneros, mostram uma grande diversidade genética nesta região. A variabilidade destas espécies oferece resistência à fusariose e possiveimente a outras doenças (Souto, 1981). Como no caso do abacaxi, o maracujá (Passiflora edulis Sims) aparece amplamente distribuído na Amazônia, sem ser definido o centro de oirigem desta espécie (Salomão, 1980). Dezenas de espécies afins ocorrem na região Amazônica e merecem uma coleta intensiva para identificar-se, avaliar e conservar o material mais interessante para programas de me. Ihoramento já sendo desenvolvido em Jaboticabal, SP e Sergipe. Tanto as espécies Ananas e Pseudoananas como as de Passiflora estão ameaçadas pela erosão genética dada a expansão das áreas cultivadas.

Nas listas anteriormente citadas, nota-se a predominância das espécies de palmeiras, pois a região Amazônica é muito rica de espécies desta família. Na opinião dos pesquisadores do INPA e de outros países da América Latina. entre as palmeiras com maior potencia! econô. mico destaca-se a pupunha que era uma das mais importantes culturas perenes dos índios dos trópicos úmidos americanos (Camacho, 1972) e sua domesticação é tão antiga que até agora não se sabe que espécie, ou espécies silvestres foram seus progenitores. A distribuição da pupunha na Amazônia se estende até os limites da bacia Amazônica em todas as direções e ccorre também no restante do norte da América do Sul e América Central onde as condições climáticas the são favoráveis. Seu fruto é uma importante fonte de caroteno (pró-Vitamina A), proteínas, óleos, graxas e carboldratos e às vezes sua safra é razão suficiente para grancies festas indígenas. Análises feitas pelo Dr. David Arkcoll e a eq̧uipe do Laboratório de INutrição do INPA tem mostrado que a pupunha possui uma enorme diversidade genética quanto ao teor de Vitamina A, "proteinas e óleos. Além de seu frutc, a pupunheira também produz um excelente palmito de maior tamanho do que os das
Euterpe spp. atualmente exploradas. A espécie cresce em touceiras, pois geralmente perfiIha livremente, por isto pode ser explorada como cultura permanente a longo prazo. Das pesquisas conduzidas pelo INPA, a Amazônia Brasileira tem três áreás de especial interesse para a coleta de material genético de pupunha com características importantes. A primeira é a do rio Amazonas, da foz até acima de Santarém; aí as plaritas produzem com grande número de frutos, freqüentemente, mais de duzentos. A segunda é a do rio Solimões, cujas palmeiras produzem cachos menores porém com frutos maiores, geralmente menos oleosos, com excelentes qualidades para o consumo. A terceira refere-se ao alto rio Negro, cujos frutos são parecidos com os do rio So. limões porém são menos oleosos chegando a ser tão secos que podem facilmente se desintegrar transformando-se em farinha. Outras áreas de interesse são as dos rios Madeira e Purus no Sudeste, os rios Japurá e Içá no Noroeste, os tributários do meio Amazonas. Nesta região Amazónica, existem outras espécies de Bactris que devem ser conservadas e ava. liadas. A ameaça de erosão genética de pupunha não é preocupante, pois são sempre protegidas pelo caboclo, porém o mesmo não pode ser dito das espécies afins que normalmente não são usadas pela população.

A castanha-do-Brasil ou castanhado-Pará constitui outra espécie frutífera nativa com grande expressão regional de reconhecido potencial econômico. Suas árvores estão entre as de maior porte da terra firme e suas amêndoas constituem importante produto de exportação, são muitc apreciadas pe!o sabor agradá. vel e pelo excelente valor proteico que apresentam devido ao alto teor de metionina. A espécie apresenta grande variabilidade genética manifestada na produtiviciade individual, tamanho da amêndoa, número de amêndoas por ouriço, compatibilidade entre indivíduos, teores de óleo na amêndoa e resistência a pragas e doenças. Assim sendo, os trabalhos do CPATU são direcionados à coleta de germoplasma caracterizado pela qualidade e produtividade. A castanha-do-Brasil constitui uma das espécies de maior interesse econômico e está atua!mente muito ameaçada pela erosão gené- 


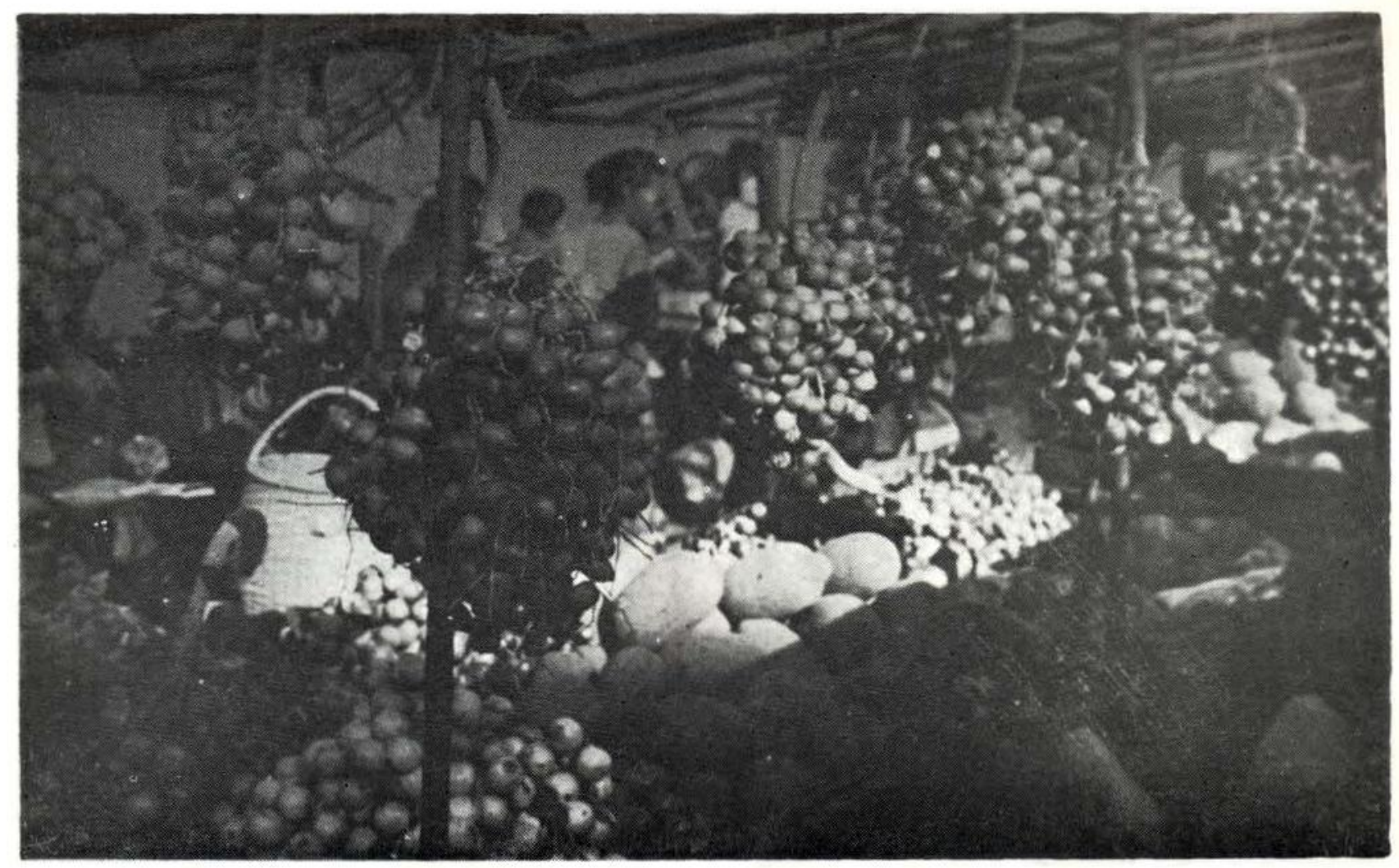

Foto 1 - Variabilidade genética de frutos de pupunha encontrada no mercado "Ver-o-Peso", Belém, PA; observase também na banca a presença de alguns frutos de cupuaçu.

tica, face à expansão de projetos de colonização e pecuária em grandes extensões de sua distribuição no Brasil.

O guaraná é um cipó de cultura pré-colom. biana nativa da Amazônia. Antes da chegada dos portugueses, os índios Maués já tinham selecionado guaraná de boa qualidade que posteriormente recebeu a denominação de $P$. cupana var. sorbilis, o que é ainda hoje o único material usado nas plantações. Sua importância se destaca pelo seu alto conteúdo de alcalóides presentes na semente, principalmente a cafeina. É por isso que a demanda para o produto é cada vez maior, tanto pela indústria de refriçerantes como pela farmacêutica. Mesmo na variedade sorbilis, encontra-se muita variabilidade nos teores de alcaloides, tamanho da semente, produção das plantas e hábito de crescimento (Kato, 1980). Existe uma outra varicdade, a $P$. cupana var. cupana que ocorre no noroeste da bacia Amazônica e muitas outras espécies de Paullinia potencialmente úteis num programa de melhoramento (Kato, com pes.). O sucesso do programa de melhoramento da UEPAE/EMBRAPA trará consigo a ameaça de erosão genética intensa da principa! variedade desta espécie porque as variedades melhoradas naturalmente substituirão as varie. dades primitivas usadas atualmente. Os recursos genéticos das outras espécies do gênero já estão sendo degradados pelo desenvolvimen. to regional.

A caiaué é o dendê do Pará, e está sendo estuciada nos últimos anos face ao seu potencial na hibridização com o dendê africano. Esta espécie ocorre espontaneamente nas terras baixas da bacia do baixo rio Sclimōes, baixo rio Negro, Rio Branco de Roraima, alto rio Amazonas a talvez no baixo rio Madeira, rio Furus e mais alguns; em síntese o centro norte da bacia Amazônica (Osi, et al., 1981). A caiaué é portadora de genes para porte reduzicio, resistência a algumas doenças e algumas partes das populações mencionadas po- 


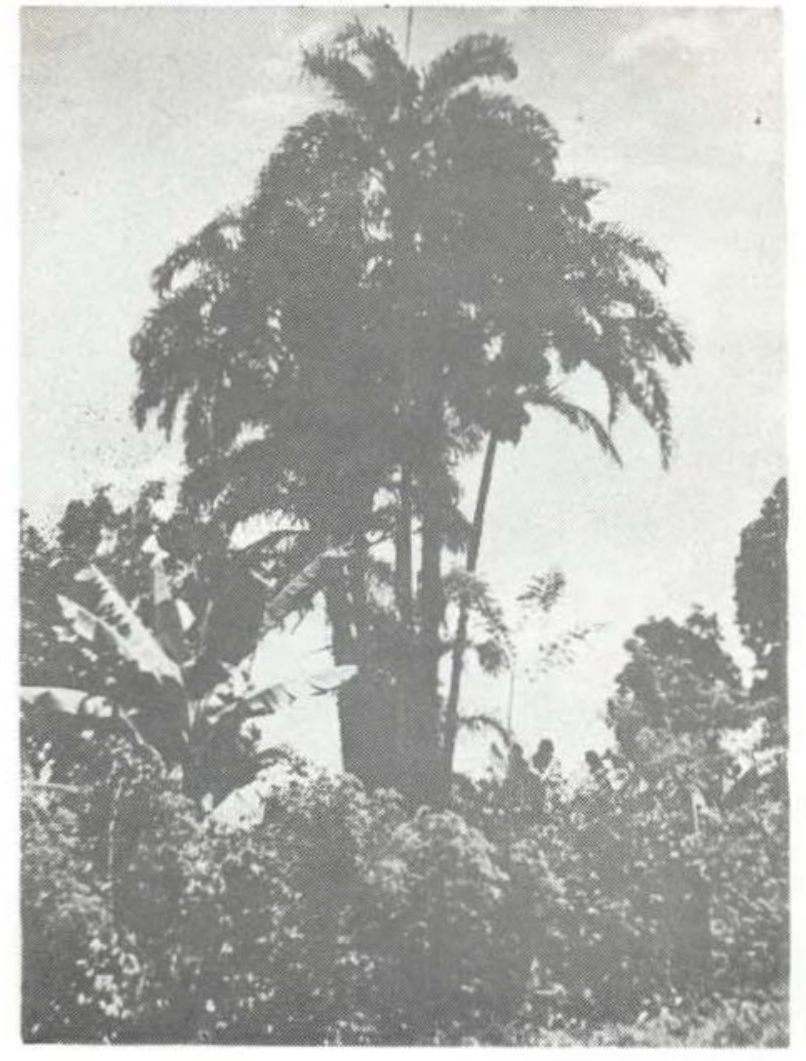

Foto 2 - Arvore de pupunha mostrando seu hábito de crescimento em touceira que favorece sua exploraçāo para palmito.

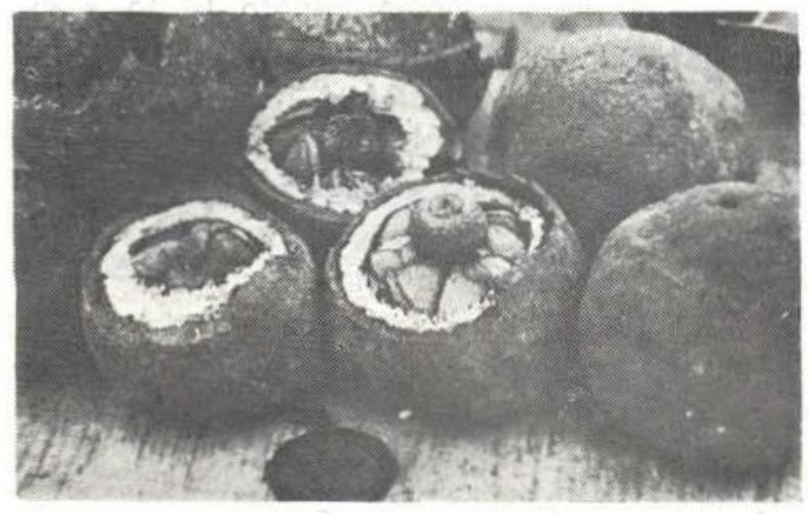

Foto 3 - Ouriço de castanha-do-brasil mostrando a forma en que as amêndoas estão organizadas. Número e tamanho de amêndoas são caracteres de importância na seleção de castanha.

dem oferecer copas reduzidas também. Até o presente, as características dos frutos híbridos não são muito interessantes exceto para variabilidade nos ácidos graxos, porém é necessário lembrar que as pesquisas neste campo ainda estão na fase inicial. A erosão genética dessa espécie será lenta, os agricultores normalmente não cortam todas as árvores de caiaué quando realizam um roçado ou área de pastagem. As extensas coletas em andamento pelo CNPSD permitirão conservar valioso germoplasma desta espécie.

Para a produção de palmito destaca-se o açai-do-Pará, o qual está especialmente amea do de erosão genética dada a grande explora. ção de algumas populações nativas para a industrialização do palmito. Apesar da campanha e dos ensinamentos do $\mathrm{Dr}$. Calzavara (1972) sobre o açaí-do-Pará, o plantio desta espécie tem sicio muito limitado, não chegando nem perto de atender a demanda de palmito. A exploração ficou tão violenta que, em 1978, o governo do Estado do Pará chegou a proibir seu corte fora das áreas de plantação. Seu fruto também dá um suco muito nutritivo, de um sabor agradável. Por causa da expansão

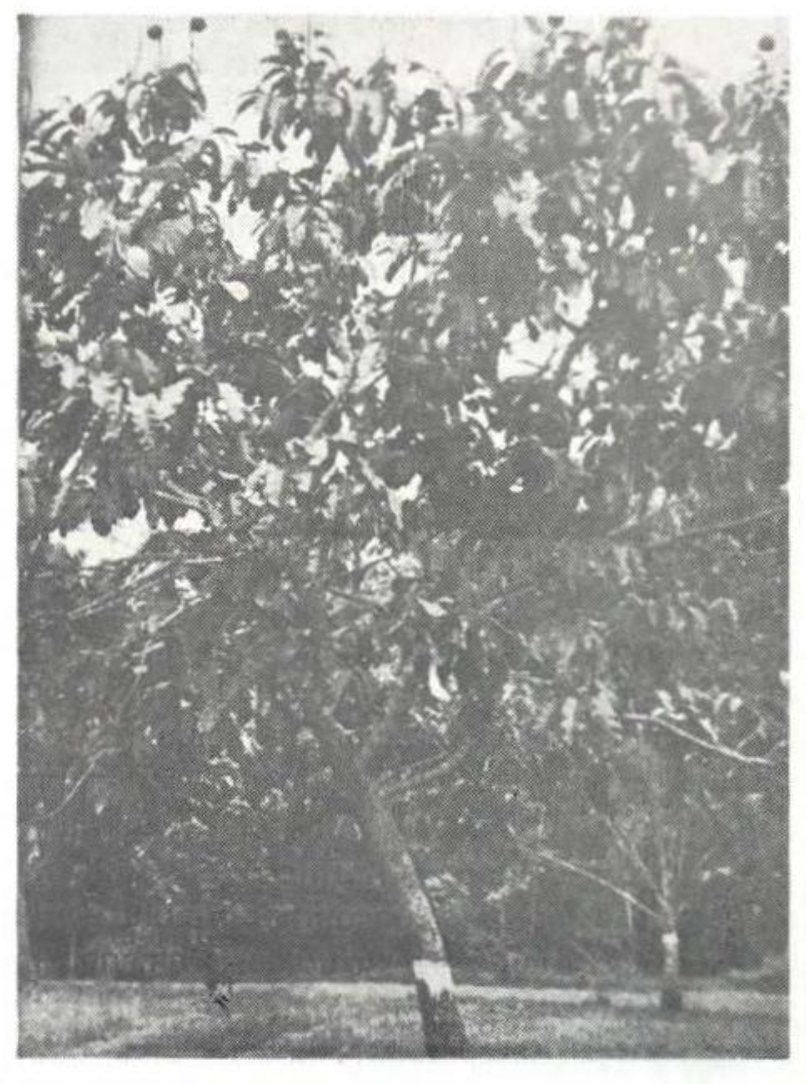

Foto 4 - Arvore enxertada de castanha-do-brasil com 12 anos, em fase de produção, CPATU-Belém, PA. 


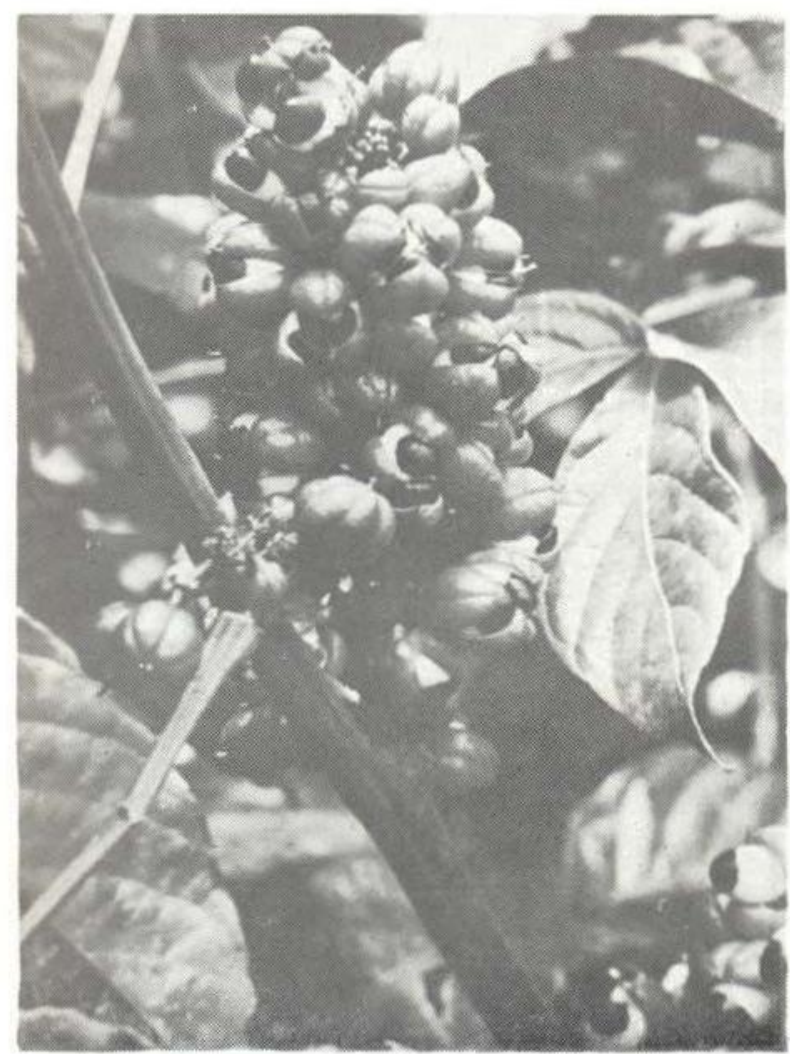

Foto 5 - Cacho de frutos de guaraná com sementes à mostra.

da indústria de extração de palmito, acreditase que o açaí-do-Pará já está seriamente erodido geneticamente em diversas áreas de sua distribuição, apesar de seu hábito de crescimento em touceira. Nenhuma instituiçã̃o Amezônica está interessada no estabelecimento de um banco de germoplasma de açai-do-Pará. nem das espécies afins.

Também pare exploração do palmito, o jaus. ri (Astrocaryum jauari Mart.), do rio Negro. está sendo utilizado. Como a pupunha e o açaí-do-Pará, o jauari cresce em touceiras. Pouco se sabe sobre esta palmeira além de dados taxonômicos e que vegeta nas ilhas do rio Negro, que são periodicamente alagadas. A companhia que está explorando o palmito desta espécie não está atualmente causando preocupação sobre a degradação genética do jauari, porém renhuma instituição até o mo. mento demonstrou interesse em preservar esta espécie.
Diversas palmeiras tem potencial para a produção de óleo comestivel, incluindo-se aqui o patauá (Jessenia bataua (Mart.) Burret.). Uma espécie de Jessenia da Venezuela produz um óleo comparável ao azeite de oliva (NAS, 1975). O patauá é uma fonte tradicional de óleo comestível na Amazônia, e teve ssu uso diminuído após a introdução de óleo enlatado, fenômeno que, aliás, é muito freqüente nestas circunstâncias, causando o desuso de muitas outras espécies oleríferas nativas. Também o muru-muru (Astrocaryum murumuru Mart.) foi uma importante fonte de óleo regional (Calza. vara, 1979). Estas espécies, e as palmeiras em geral, estão sofrendo uma erosão genética lenta, porém contínua. Como no caso da caiaué, os agricultores normalmente deixam palmeiras em pé, especialmente as espinhosas, quando derrubam uma área. Se estas sobrevivem à queimada elas têm uma boa chance de permanecer para muito tempo.

A Amazônia Oriental é o centro de origem do cupuaçu, cujo fruto contém uma polpa agri-

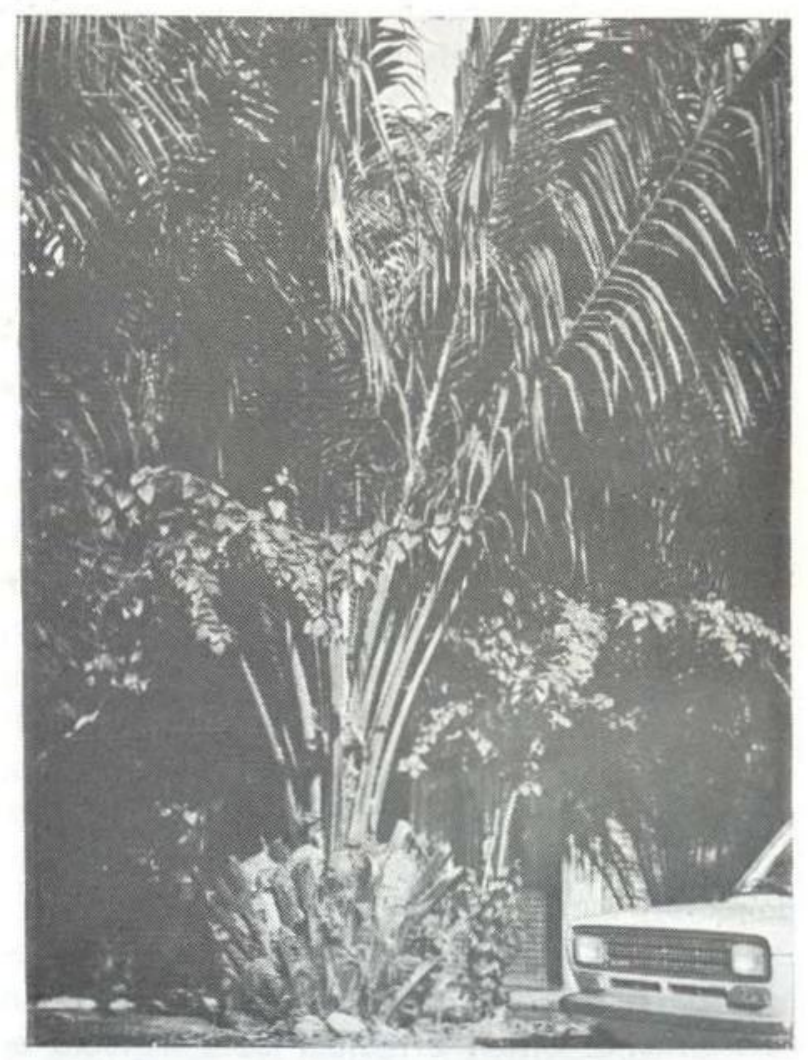

Foto 6 - Árvore jovem de caiaué, em fase de produção, no campus do INPA. 
doce, muito agradável, envolvendo os caroços que tem potencial para fazer chocolate branco. Segundo Calzavara (comunicação pessoal), há anos, a Nestlé vem procurardo sementes de cupuaçu para fazer chocolate branco mas até agorã não conseguiu o suficiente, já que não existiam plantações de cupuaçu. Diversas das indústrias usam muito a polpa do cupuaçu para dar sabor ao sorvete, fazer sucos, geléias, compotas, etc., porém só recentemente começaram a ter suas próprias plantações. Os técnicos da CEPLAC que buscam variantes genéticos encontram: diverscs indivíduos de cupuaçu que parecem ser resistentes à Vassoura de Bruxa (Crinipellis perniciosa (Stahel) Singer) (Basil Bartley, com. pess.). O extinto IPEAN selecionou uma árvore de cupuaçu que produzia frutos sem sementes e esta que deveria ser bem aceita pelas donas de casa, pois a separação da polpa do caroço é muito trabalhosa, porém surpreendentemente, a divulgação desta variedade nunca despertou o interesse dos agricultores em geral. Somente alguns chegaram a produzir quantidades comerciais. Sendo o centro de origem desta espécie na Amazônia Oriental, a ameaça de erosão genética é séria, já quie é nesta região que o desenvolvimento agrícola tem sido mais intenso com grandes projetos pecuários, colonizações e agora o Programa Carajás e a Hidrelétrica de Tucuruí. Até agora nenhuma instituiçäo tem coletado gernioplasma desta espécie, embora o INPA pretenda fazê-lo assim que recursos humanos e financeiros o permitam.

Uma outra fruteira da Amazônia de grande interesse e aceitação é o bacuri cujo fruto contém uma polpa muito apreciada e bastante usada pelas agro-indústrias. Recentemente, uma interessante variação no formato do fruto foi encontrada na ilha de Marajó, por pesquisedores do Museu Goeldi, com frutos maiores, casca marrom-rugosa em lugar de verde-amarelo-iisa, freqüentemente com 6 segmentos de polpa em vez de cinco que é mais freqüente Dada a facilidade com que o bacuri produz rebentões das raízes após o corte do tronco é normalmente difícil erradicar esta espécie e, dada sua pepularidade regional, não se acredita que a erosão genética tenha sido séria, ou que seja preocupante no presente.

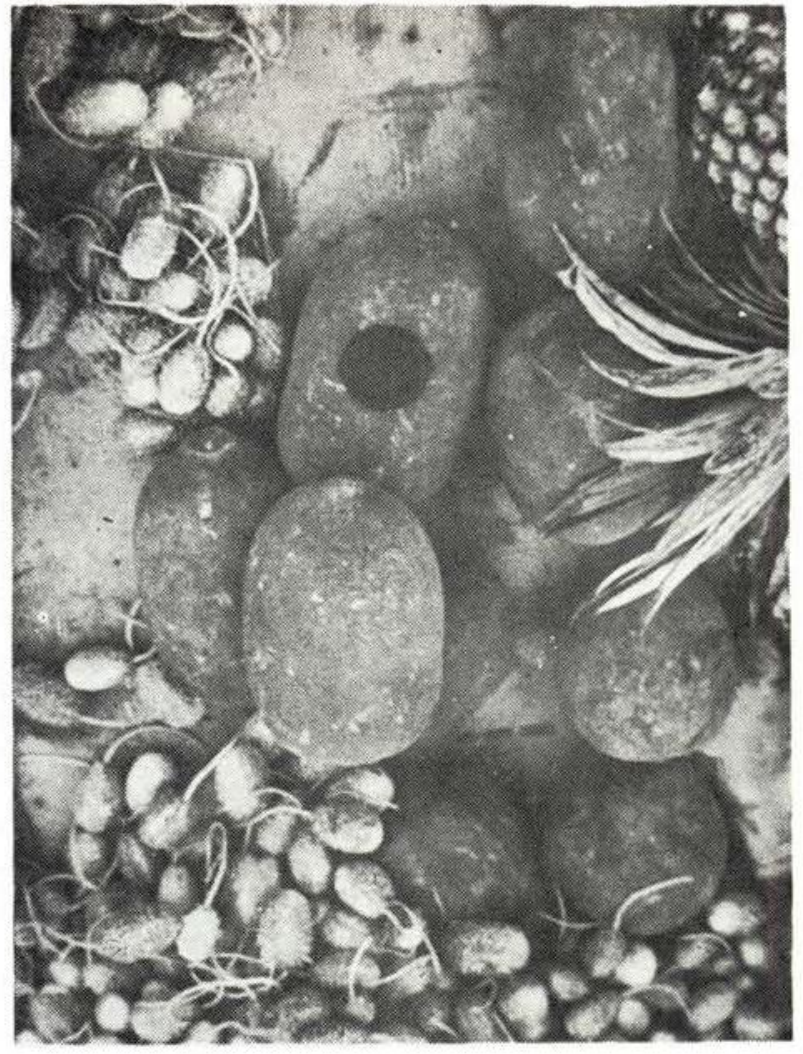

Foto 7 - Fruto de cupuaçu na Feira do Produtor Rural, Manaus, AM. Observa-se diferentes formas e tamanhos dos frutos.

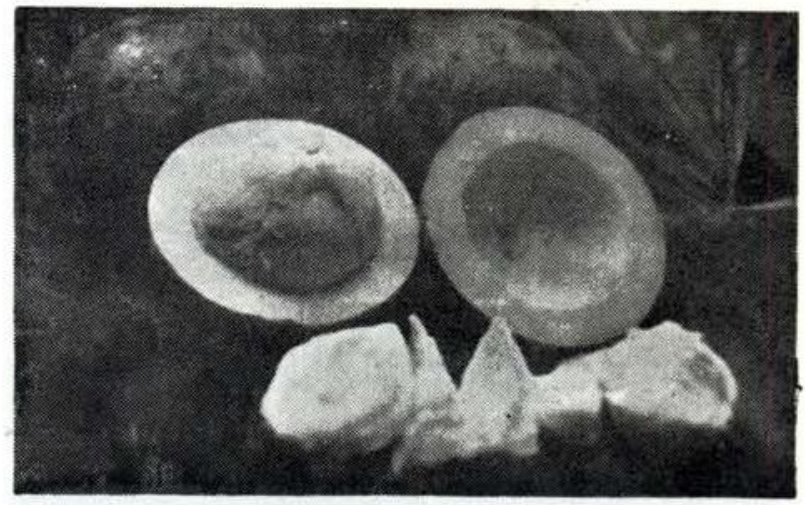

Foto 8 - Frutos de bacuri do Pará, inteiros e partidos. Alguns segmentos do fruto estão sem sementes, "fiIhotes", e são as partes preferidas.

O murici é uma fruteira que encontra sua melhor qualidade e maior expressão econômica na região oriental. É um fruto pequeno com muitá polpa do qual se extrai excelente suco com sabor especial usadio para sorvetes. A produção pode ser muito grande e a espécie 
vegeta bem nos solos pobres e arenosos de regiăo, sendo encontrado nas áreas disturba. das e nas capoeiras. Dadas sua popularidade e sua competitividade nas áreas de crescimento secundário, acredita-se que o murici ainda não esteja ameaçado pela erosão genética.

$\mathrm{Na}$ família cias Sapotáceas, ocorrem diversas espécies com material genético interes sante, de ampla distribuição pan-Amazônica. O abiu é bem conhecido na região como um fruto pequeno com polpa bastante agradável. Na regiäo do alto rio Solimões, existem variantes que produzem frutos de 800 gramas, tão sabo. rosos quantos os pequenos. O sapoti ocorre em diversas populações de alto interesse na regiăo. Na ilha de Marajó, encontra-se uma população que produz frutos grandes e na vila de Silves, AM, existe uma população de frutos igualmente grandes com uma polpa firme por alguns diias após a maturação, uma característica muito interessante para exportação. Estas espécies, a primeira indígena e a outra exótica. porém com espécies afins na região, são tão populares que as plantas dos quintais da região constituem um valioso reservatório de germoplasma. As outras espécies destes gê. neros, Pouteria e Manilkara, estão severamen. te ameaçadas pela erosão genética porque fornecem madeira de boa ou razoável qualidade.

O piquiá (Caryocar villosum (Aubl.) Pers.) foi apontado pelo mesmo explorador inglês que levou a seringueira, como uma das espécies

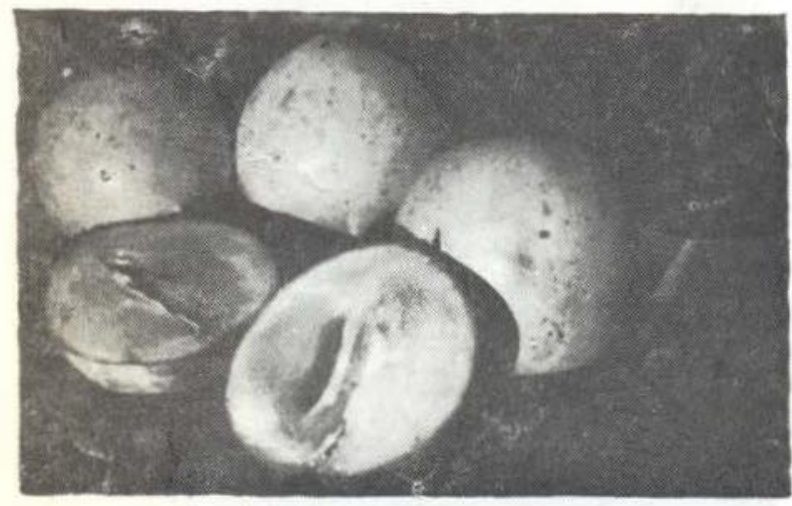

Foto 9 - Frutos de abiu procedentes do alto rio Solimões. Os frutos oblongos (como os da foto) pesam em médią $600 \mathrm{~g}$, enquanto que os redondos (nẫo mostrados) pesam em média $800 \mathrm{~g}$; são produzidos em solos férteis com elevada pluviosidade.

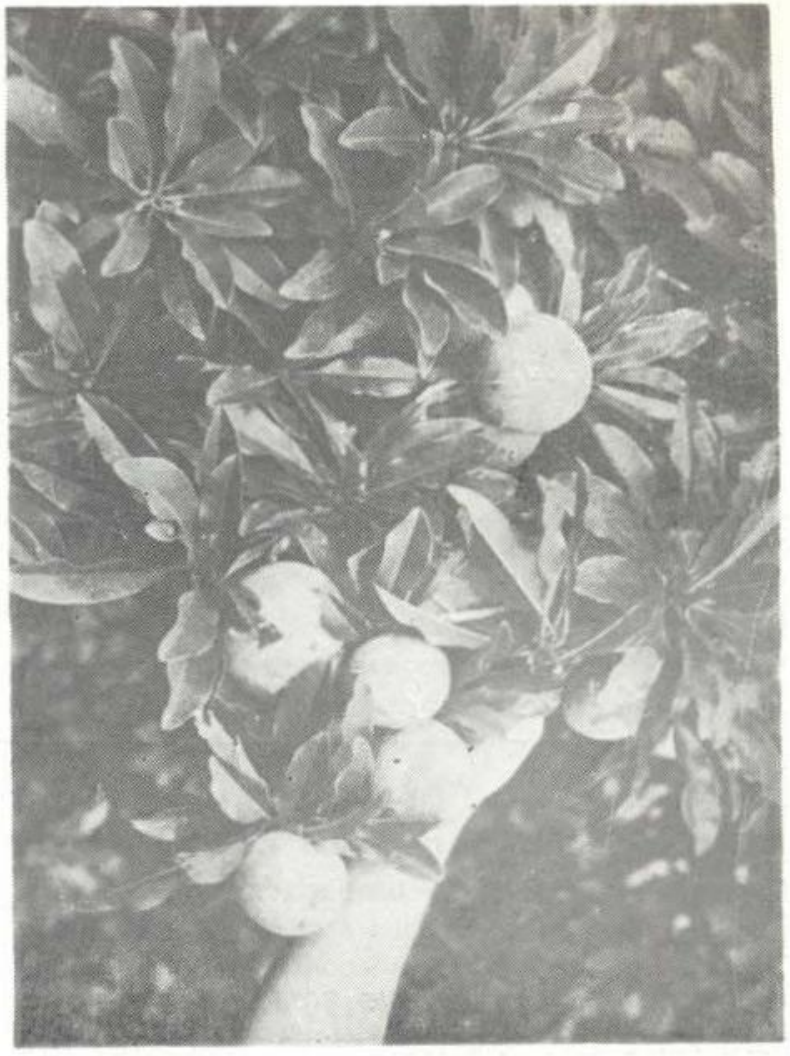

Foto 10 - Frutos e folhagem da sapoti, procedente de Silves, AM, de bom tamanho, produção e com a polpa firme após maduração.

amazônicas com maior potencial. O fruto do piquiá, como seu caroço, são ricos em óleo comestível, razão pela qual Henry Wickham recomendou o estudo desta espécie. A amêndoa do piquiá é considerada uma das melhores da região, porém poucas pessoas a usam visto ser protegida dentro do fruto por uma densa camada de espinhos. A madeira desta espécie é considerada de alto valor comercial, o que é causa de preocupação em termos da perda de seus recursos genéticos. Felizmente as instituições de pesquisa florestal consideram o piquiá uma espécie promissora para plantações, de modo que algum germoplasma pode ser conservado desta forma.

C caju-açu (Anacardium giganteum Hanc. ex Engler.), parente do caju comum amplamente distribuído ria região, tanto quanto outras espécies do gênero, podendo ser importante fonte de resistència à Antracnose em caju. Esta, e outras espécies do gênero, possuem 


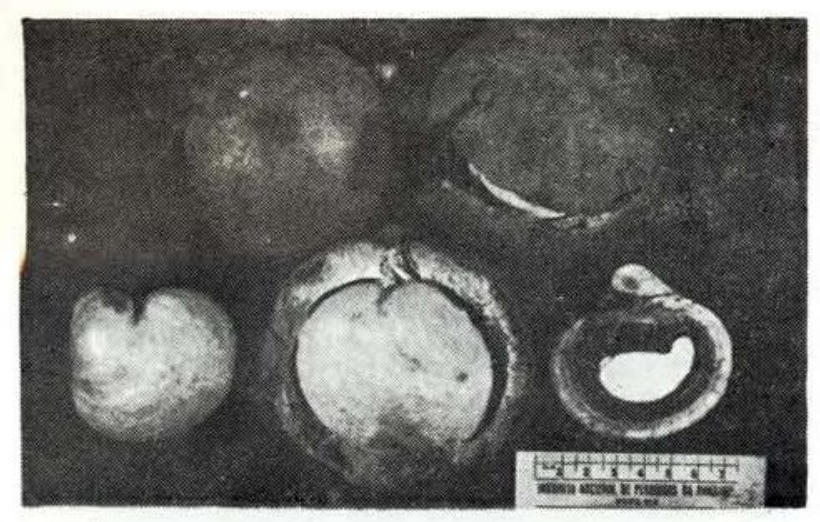

Foto 11 - Frutos do piquiá, inteiros e partidos. A amêndoa (oleosa) e o mesocarpo ao redor dos espinhos (amidoso e oleoso) são comestiveis; o pericarpo é solto quando maduro, rico em taninos e amido, porém năo é comestível.

muita variabilidade genética na região e em? alguns lugares estão ameaçadios pela erosãc genética.

Da mesma torma que acontece com o gênero Anacardium, encontram-se espécies relacionadas com a goiaba, algumas das quais podem ser importantes para seu próprio melhoramento, como o araçá-goiaba ou araçá-pera. Outros gêneros e espécies da família Myrtaceae merecem atenção graças aos elevados teores de ácido ascorbico como, por exemplo. camu-camu com $1950 / \mathrm{mg}$ Vit.C/100 gr. de fruto (Instituto Nacional de Nutricion, 1974), e por seu sabor muito agradável para a indus trialização de sucos, sorvetes, doces; como também $o$ araçá-boi com frutos grandes e pro. duzindo continuamente durante todo o ano, oferecendo alto potencial agro-industrial. O germopiasma destas Mirtáceas e outras espé cies afins é muito valioso porém está ameaçado de erosão genética em muitas áreas.

A graviola e o biribá (Rollinia mucosa (Jacq. Baill.) são ambos da família Anonaceae. A graviola, especialmente é muito procurada para a industrialização em diversos países, inclusive no Brasil. Na região, encontram-se árvores produtivas e indivíduos com frutos com excelentes características de forma, tamanho e sabor. Este material é quase todo encontrado nos quintais e residências, sendo relativamente protegido, mas deve ser coletado para avaliação. Existem! ainda outras espécies dos gêneros Annona e Rollinia que constituem valioso germoplasma para o melhoramento das espécies principais. O araticum (Annona montana Macf.) é um exemplo de uma espécie muitc afim da graviola que pode ser importante. com @ também $\triangleq$ condessa (Annona glabra L) que poderia servir como porta-enxerto. A graviola scfre relativamente pouca erosão genética porque é uma planta de quintal, porém as Jutras espécies afins são ameaçadas porque são silvestres e menos populares.

A Amazônia Ocidental possui importantes fontes de diversidade genética do mapati, também conhecida como cucura pelos índios Tucanos do alto rio Negro e como uvilla no Peru e Colombia e outros países circunvizinhos onde ocorre. A árvore do mapati assemelha-se à da Cecropia sp. e produz fruto semelhante ao da uva, não somente na cor, forma e sabor, mas também, no fato de ser produzido em cachos. Experimentos realizados pela D. Giselda Ranzani mostram a possibilidade de fermentação do fruto para a produção de vinho de boa

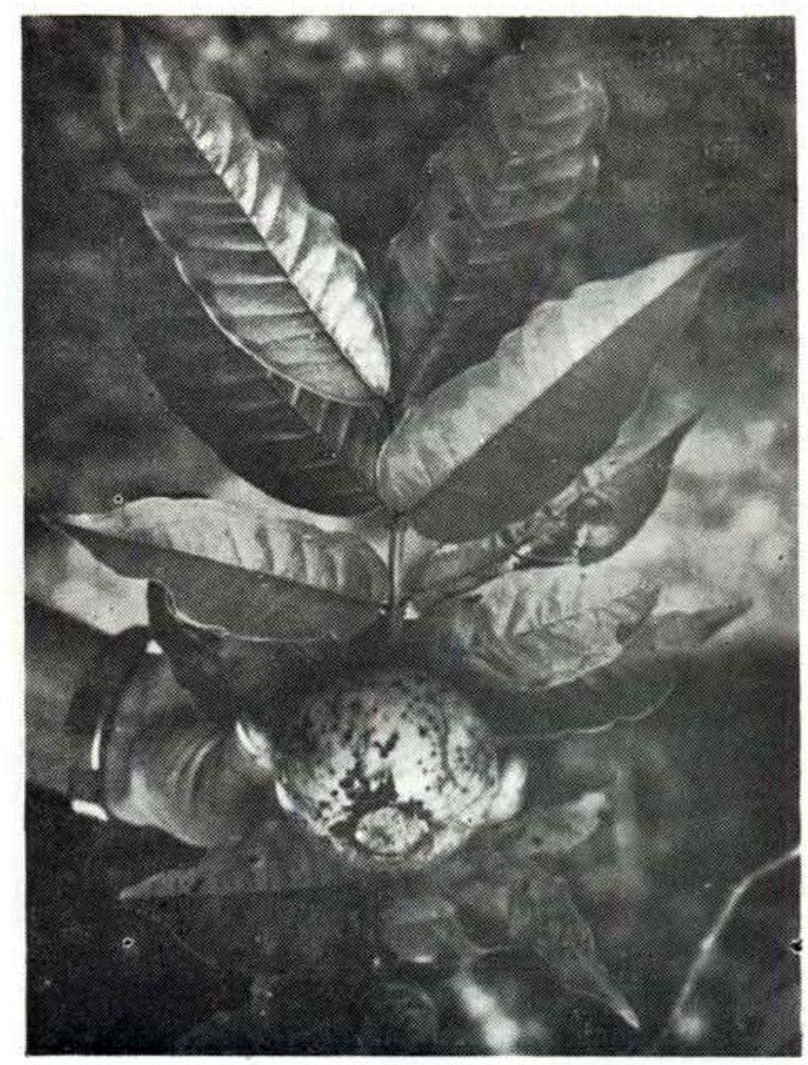

Foto 12 - Fruto e folhagem de araçá-pera. Detalhes da forma do galho. O fruto é semelhante a goiaba. 


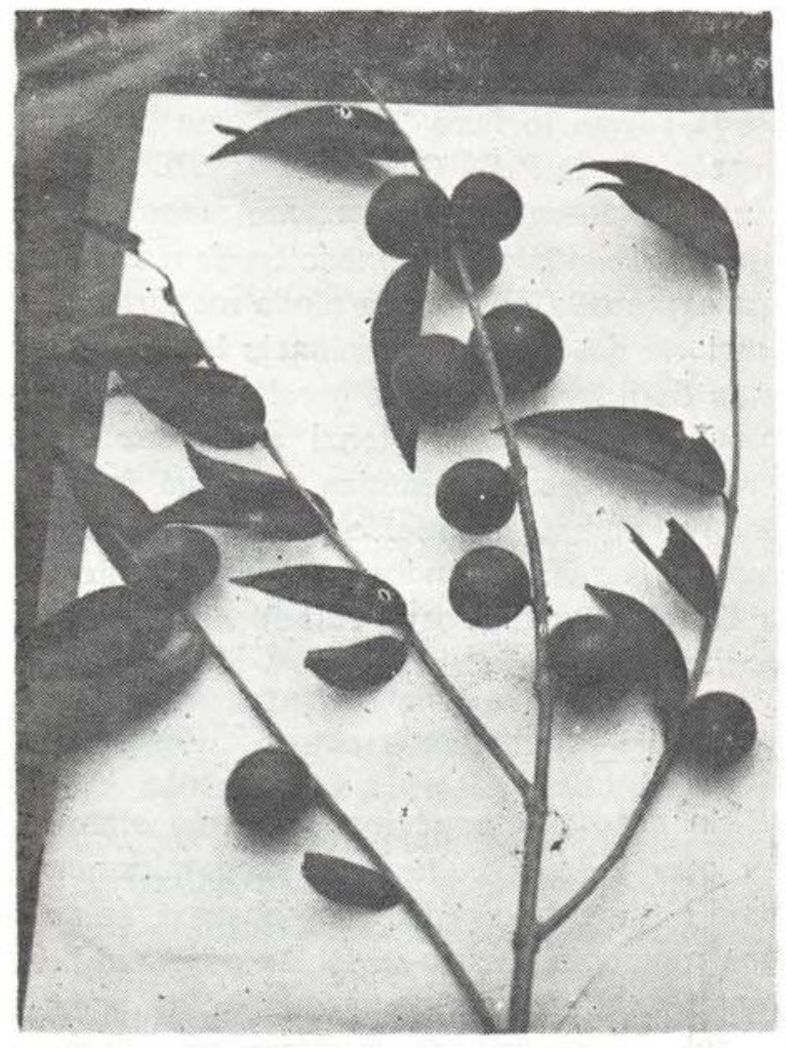

Foto 13 - Frutos e folhagem de camu-camu. A espécie é típica da várzea porém se adapta bem à terra firme.

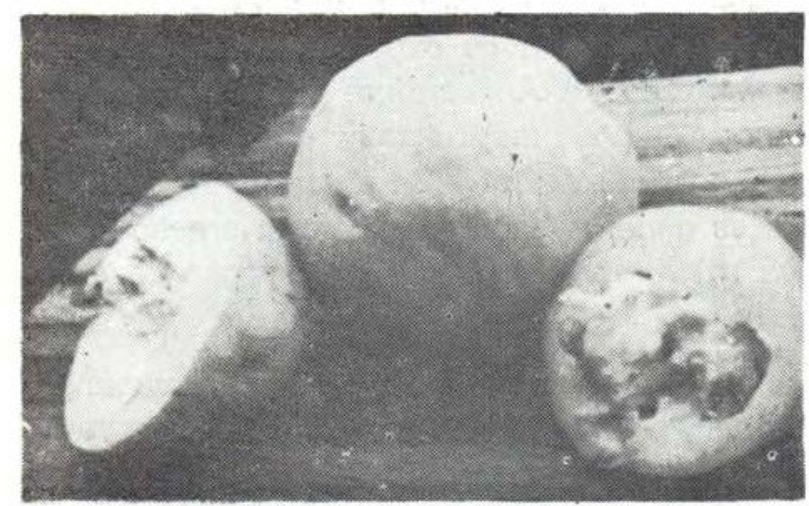

Foto 14 - Fruto de araçá-boi, inteiro e partido. Em solos férteis ou com adubação o fruto chega a pesar até $800 \mathrm{~g}$, como os da foto.

qualidade. Dado o seu ciclo reprodutivo de somente três anos, o melhoramento genético desta espécie, continuando o trabalho dos Ticunas", daria resultados satisfatórios em poucos anos. No Brasil, esta espécie não é ameaçada de erosão genética, pois é tão popular e rús- tica ciue o povo elimina as árvores e, a espécie se semea naturalmente, então expandindo as populaçōes.

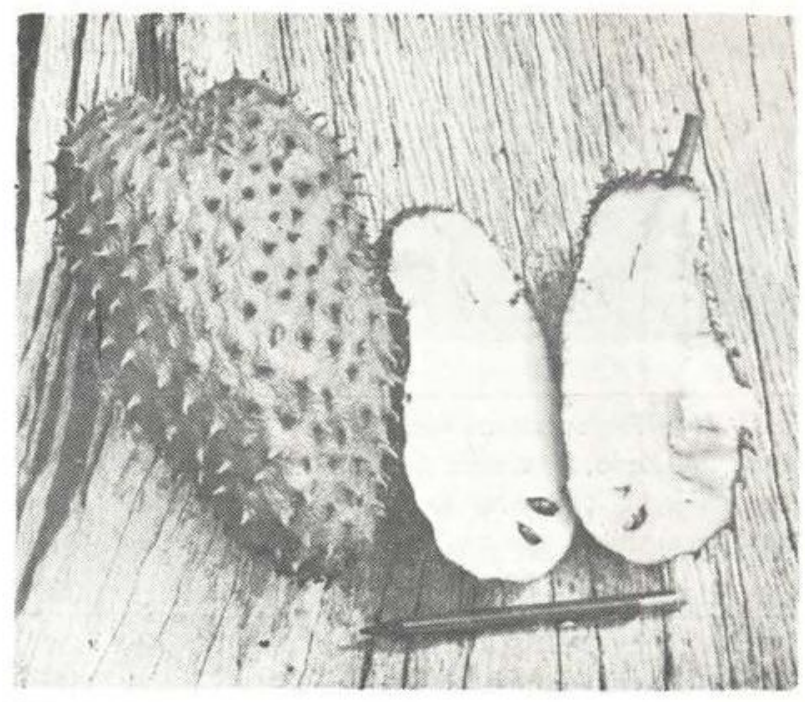

Foto 15 - Fruto da graviola, inteiro e partido. A forma do fruto é devido a eficiência de polinizaçăo, podendo os ovulos não fecundados permanecerem pequenos. Detalhe do início de uma broca do fruto, uma das principais pragas.

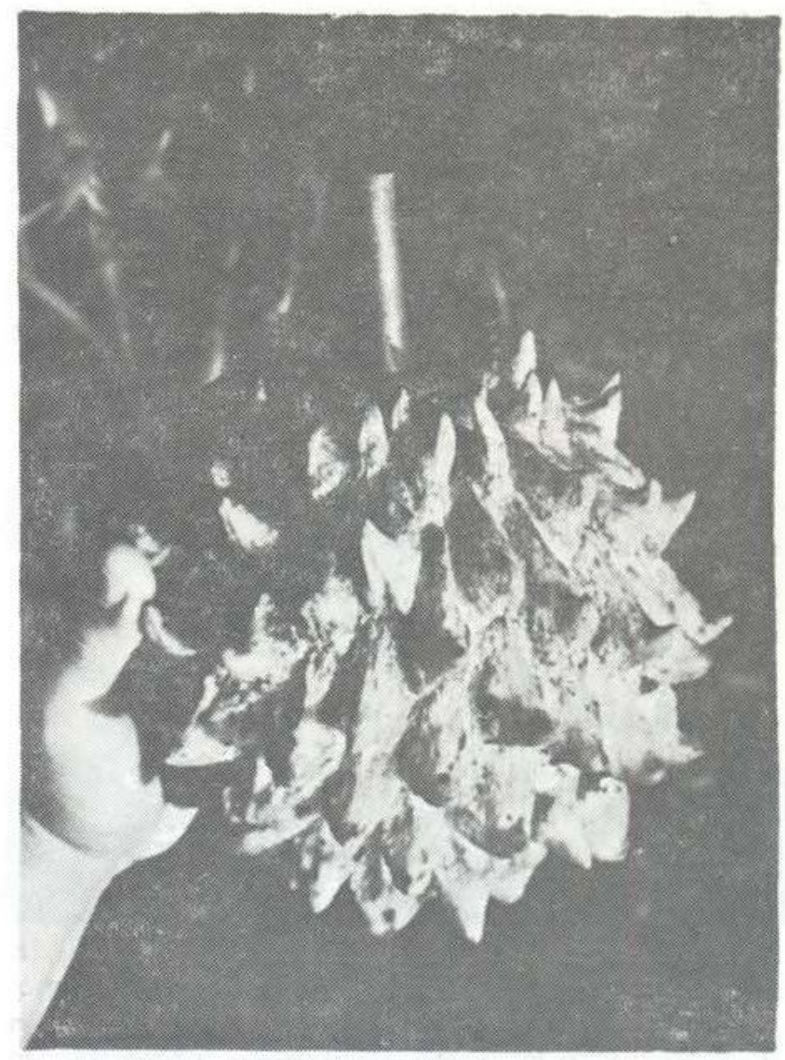

Foto 16 - Fruto de biribá do alto rio Solimōes que pode pesar até $4 \mathrm{~kg}$, como o desta foto. 


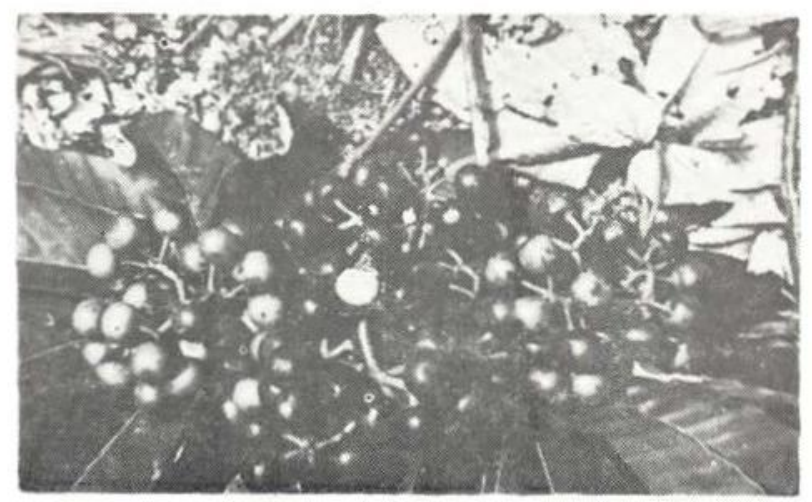

Foto 17 - Frutos de mapatí, a "uva da Amazônia", inteiros, maduros, imaduros a partidos em contraste com a camada de folhagem. Detalhes da forma do fruto e sua apresentação em cachos, o fruto partido mostra a polpa e semente.

Além do mapati, destaca-se a sapota que tem uma distribuição na Amazônia Ocidental Brasileira muito similar a do mapati. Fruto com sabor doce, agradável, que pode chegar a 1 (um) quilo de peso e 30 a $35 \%$ aproveitável. podendo uma árvore produzir mais de 6.000 frutos num ano, em solo fértil (Clement, 1981). Esta fruta apresenta potencial para consumo "in natura" pois seu aproveitamento industria! caseıro não tem produzido resultados animado. res. Como o mapati, esta espécie não parece ameaçada pela erosão genética na Amazônia Brasileira.

Resumidamente, apresentamos neste tra. balho as listas de prioridades atuais das instituiçōes, com avaliação e comentários sobre as

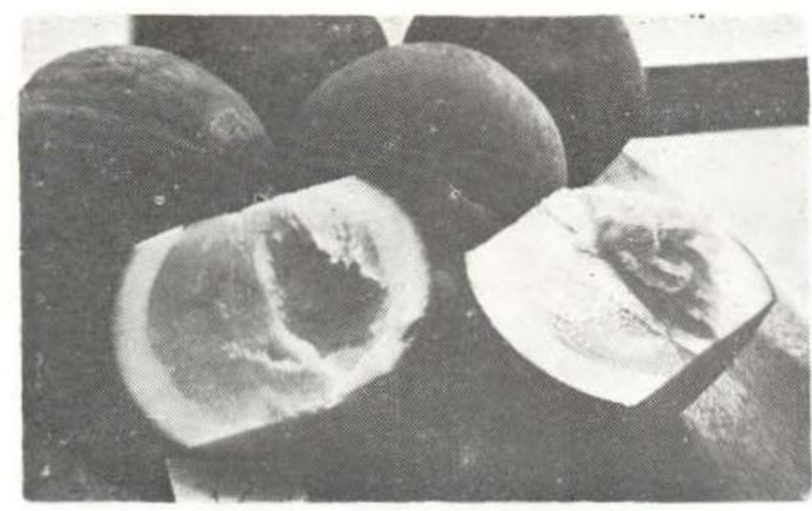

Foto 18 - Frutos de sapota, inteiros e partidos, provenientes da região de Tefé, AM, onde crescem em terra preta do índio e chegam a pesar $1.200 \mathrm{~g}$. Os da foto pesam em média $425 \mathrm{~g}$, são um pouco fibrosos, muito doces e suculentos. pesquisas em andamento. Não se pretende cobrit todas as espécies mencionadas nas coleções porque o livro "Frutas Comestíveis da Amazônia", de P.B. Cavalcante (1976 e 1979) o fez amplamente. É importante ressaltar que as outras espécies não mencicnadas aqui têm uma expressão econômica ainca menor do que a maioria das espécies regionais incluídas nas listas de prioridades. Em geral, esta baixa ex. pressão econômica regional se traduz numa ameaça de erosão genética na atual fase de desenvolvimento na região, especialmente nas áreas de pecuária, Rondônia (com a colonização na Estrada Cuiabá-Porto Velho) e na área do Programa Grande Carajás.

\section{Conclusões}

No caso das espécies frutíferas amazônicas que já sãc cultivadas economicamente, como é o caso do cacau e do abacaxi, as coleçöes regionais e extra-regionais possuem boas amostragens de germoplasma feitas, com a intenção prioritária de explorar mais intensivamente a região Amazônica. A CEPLAC tem realizado algumas expedições de coleta e pretende expandílas nos próximos anos (B. Bartley, com. pes.) e o CENARGEN, em colaboração com o CNPMF e a EPACE, também pretende expandir as expedições de coleta de Ananas spp. e Anacardium spp. Com os esforços destas instituições esperam coletar uma razoável amostra da diversidade genética destes gêneros antes que sofram erosão genética ırreversível devido à colonização da Amazônia.

Quanto a castanha-do-Brasil e da pupunha. a situação é um pouco privilegiada, pois estas espécies são muito populares na região, e por isto pode-se esperar que a erosão dos recursos genéticos destas fruteiras seja menos drástica a curto prazo. No caso da castanha-do-Brasil, a espécie é protegida por lei, de modo que sofre ainda menos agora do que sofria antes. No entanto, vários castanhais estão localizados em áreas atingidas pelos grandes projetos agropecuários onde a lei não é respeitada durante a preparação dos pastos. Muitas vezes o proprietário deixa as árvores de castanha em pé, mas o fogo logo acaba com sua intenção de cumprir a lei. Desta maneira existe uma 
certa necessidade de explorar melhor as regiōes dos grandes projetos para determinar 0 valor do germoplasma alí existente e para con. servar uma amostra representativa deste. Convém mencionar também os castanhais a serem destruídos pelas inundações da barragem do Tuctiruí. No caso da pupunha, cuja distribuição na Amazônia está diretamente ligada a presença do homem, espera-se que a erosão genética ocorra somente devido a intrúdução de variedades melhores. Desta forma, encontra-se o dilema de que a distribuição das plantas selecionadas pelos indios (Kerr \& Clement, 1980) ou pelos programas de melhoramento podem causar a eliminação de recursos genéticos va. liosos por outras razões. Assim, somente efetuando-se uma coleção acelerada do material primitivo, conservar-se-á este germoplasma.

O guaraná está recebendo a atenção prio ritária da UEPAE/EMBRAPA, com a colaboração do CPATU/EMBRAPA. As coleções da varieda. de $P$. cupana var. sorbilis precisarão ser ampliadas dentro de breve para correr â frente do dilema mencionado no caso da pupunha. A coleta de espécies afins, é urgente, pois este material genético está seriamente ameaçado de perdas em toda região, porque nenhuma outra espécie do gênero tem valor comercia!.

Assim pode-se concluir que os casos acima mencionados estão sendo orientados de tal forma que uma razoável amostra da variabilidade genética de cada espécie será coletada e conservada e então protegida da erosãc genética conseqüência da colonização da Amazônia. Mas este esforço inclui somente cinco espécies, e as outras espécies?

A situação dos recursos genéticos das outras espécies com potencial econômico e respectivas espécies afins é precária. A rápida ocupação de diversas áreas da Amazônia Brasileira por colonos de outras partes do país está causando perdas consideráveis entre as populações de espécies frutíferas. Isto ocorre peio fato de que o colono normalmente vem de outras regiões fora da Amazônia e não tem conhecimento das fruteiras Amazônicas, de modo que ele não hesita em derrubá-las para plantar banana etc. Esta situação é ainda mais grave no caso de espécies regionais de sabor muito forte e que o migrante leva tempo para conhecer e aceitar. Desta forma, a colonização da Amazônia traz consigo, inevitavelmente, a perda dos recursos genéticos de espécies frutiferas da região. Embora se reconheça a inevitabilidade da colonização da Amazônia in siste-se numa estratégia de coleta e conservação dos recursos genéticos destas espécies.

As instituições de pesquisa no Brasil e no exterior estão cada vez mais certas de que a agricultura na Amazônia precisa ser feita na base de culturas perenes, dada a sua melhor conformidade às exigências ecológicas da regiäo (Clement \& Arkcoli, 1980). Com esta nova conscientização, tornam-se essenciais as aiternativas agricolas para atender ao pequeno e médio agricultor. Entre estas alternativas, as fruteiras se destacam, graças ao alto rendimento por hectare, em termos de alimentação e rendia. Considerando estas alternativas como válidas, é preciso conscientizar o governo de que as fruteiras indígenas merecem ser pesquisadas, exigindo consideráveis investimen tos a longo prazo. Atualmente, o CENARGEN está consciente disto, porém está limitado pela falta de recursos humanos e financeiros. Restam, entretanto, as seguintes alternativas:

1. Apoio financeiro e recursos humanos do exterior, em fontes onde se encontra uma grande conscientização da situação na Amazônia. Uma vez que é impossivel evitar a colo. nização da Amazônia, estes grupos poderiam tornar-se interessados em ajuclar a conservar os recursos genéticos da região, sob a coordenação do CENARGEN;

2. Aplicar taxas aos preietos de grande porte parə pagar o resgate e conservação deste material genético na região em que eles estão se instalando. Assim, os grandes pecuaristas do sul do Pará ajudariam a cobrir os custos de coleta de recursos genéticos da castanha do-Brasil e outras espécies antes da derrubada. As companhias de colonização no norte de Mato Grosso seriam taxadas para pagar a coleta de babaçu (Orbignya spp.) e outras fruteiras regionais. $\mathrm{E}$ as companhias que buscam os incentivos do programa Polamazônia deve. riam incluir um ou dois porcento de seu orçamento para este fim. E ainda o Programa Grande Carajás deveria exigir que as firmas nacionais e multinacionais que vão se instalando na região ajudem com a conservação deste materiai. 


\section{AgRAdeCIMENToS}

Os autores desejam agradecer acs Srs Basi! Bartley (CEPLAC, BA), Benito Calzavará (FCAP), Gernack F. Souto (CNPMF), Júlio Barriga (CEPLAC, PA) e Noemia Vasconcelos (CEPLAC, AM) pelas informações sobre o estado atual das respectivas coleções, e ao $\mathrm{Dr}$. Dalmo C. Giacometti (CENARGEN) pelas suas valiosas críticas e sugestões.

\section{SUMMARY}

This article presents the history of the institutional organizations responsable for the study of fruit genetic resources indigenous to the Amazon. The past and present priority lists of CPATU/EMBRAPA, FCAP, INPA/ CNPq, UEPAE/EMBRAPA ,CNPMF/EMBRAPA, CEPLAC, CNPSD/EMBRAPA and EPACE are presented, together with the species lists of the germplasm collections and germplasm banks maintained by each institution, as well as discussion of each institution's immediate intentions for the expansion of these studies. Most of the species that appear in the priority list as indigenous to Amazonia are then considered with more detail, as well as several others with eventual economic potential. The uses of these fruits are mentioned and references are made in relation to the threat of genetic erosion faced by each species. The importance of Palmae germplasm is emphasized. General considerations are made about the status of efforts for collecting and conservation of these valuable genetic resources with special reference to the work of CENARGEN/EMBRAPA, about general and specific threats of genetic erosion in the region and some suggestions are made on the strategy for saving these genetic resources.

\section{REFERENCIAS BIBLIOGRAFICAS}

ALEUQUERQUE, M. de \& LIBONATI, V.F.

1964 - IPEAN!: 25 anos de pesquisas na Amazônia; histórico, organização, pesquisas. IPEAN, Belém, 84p.

EARROS, L. de M.

1980 - Banco ativo de germoplasma de caju. In: Simpósio de Recursos Genéticos Vegetais. Sessão I. Bancos Ativos de Germoplasma. CENARGEN-EMBRAPA, Brasilia, 210p.

CALZAVARA, B.B.G.

1972 - As possibilidades do açaizeiro no estuário Amazônico. FCAP, Bol. Téc. n. 5, Belém, $103 p$.

1978 - A*fruticultura como opção econômica para a Amazônia. In: I' Encointro Nacional de Fruticultura Tropical, Manaus. (Mimeografado).
1979 - Palestra proferida. In: Anais do Seminário "Pesquisa tecnológica em processamento de produtos agropecuários da região norte". EMBRAPA/CTAA, Rio de Janeiro, 179p.

CAMACHO, V.E.

1972 - El pejibaye (Guilielma gasipaes (H.B.K.) Bailey). In: Simpósio internacional sobre Plantas de Interes Economico de la Flora Amazonica. IICA-Trćpicos n. 93, Turrialba, Costa Rica, p. 101-106.

CAVALCANTE, P.B.

1976 - Frutas comestiveis da Amazônia. 3. ed. INPA, Belém, 166p.

1979 - Frutas comestiveis da Amazônia. Vol. III, INPA, Belém, 61p.

CLEMENT, C.R.

1981 - Considerações sobre a sapota da América do Sul. In: Anais do 19. Congresso da Sociedade Americana de Ciências Hortícolas Região Tropical. Vol. 25: 427-431.

CLEMENT, C.R \& ARKCOLL, D.B.

1979 - A política florestal e o futuro promissor da fruticultura na Amazônia. Acta Amazonica, 9 (4): 173-177 (Suplemento).

CORREA, M.P.

1926 - Dicionário das plantas úteis do Brasil e das exóticas cultivadas. 6 Vol. Imprensa Nacional, Rio de Janeiro.

FRANKEL, O.H.

1977 - Natural variation and Its conservation. In: Muhammed, A. Genetic Diversity in Plants. Plenum Press. New York. 506p.

HOEHNE, F.C.

1946 - Frutas indigenas. Inst. Bot. SP. 88p.

INSTITUTO NACIONAL DE NUTRICIÓN

1974 - Composión de los alimentos peruanos. Bol. Min. Salud., Lima, Peru, 37p.

KATO, A.K.

1980 - Banco ativo de germoplasma de guaraná. In: Simpósio de Recursos Genéticos Vegetais. Sessão I: Banco Ativo de Germoplasma. CENARGEN-EMBRAPA. Brasilia, 210p.

KERR, W.E. \& CLEMENT, C.R.

1980 - Práticas de consequiências genéticas que possibilitaram aos indios da Amazônia uma melhor adaptação às condiçōes da região. Acta Amazonica, 10 (2): 251-261.

LE COINTE, P.

1974 - Amazônia Brasileira III. Arvores e plantas úteis (indigenas e exóticas). Brasiliana, Série 5, Vol. 251. Rio de Janeiro, Imprensa Nacional, 506p.

LOVEJOY, T.E.

1979 - The epoch of biotic impoverishment, In: The endangered species: A Symposium. Great Basin Naturalist Memoirs n. 3. Bripham Young Univ. Provo (Utah). 
MYERS, $\mathrm{N}$.

1979 - The sinking ark, a new look at the problem of disappearing species. Oxford. Pergamon Press, 307p.

NATIONAL ACADEMY OF SCIENCES

1975 - Underexploited tropical plants with promising economic value. NAS, Washington, D.C. $188 p$.

OOI, S.C.; SILVA, E.B. da; MÜLLER, A.A. \&

NASCIMENTO, J.C.

1981 - Oil palm genetic resources - native E. oleifera populations in Brazil offer promissing sources. Pesq. Agropec .Bras., 16 (3): 355395.
SALOMĀO, T.A.

1980 - Botânica do maracujazeiro. In: Ruggiero, C. et al. Cultura do Maracujazeiro. FCAV, Jaboticabal, SP. 147p.

SCHULTES, R.E.

1977 - Diversas plantas comestiveis nativas do Noroeste da Amazônia. Acta Amazonica, 7 (3): $317-372$.

SOUTO, G.F.

1980 - Banco ativo de germoplasma de abacaxi. In: Simpósio de Recursos Genéticos Vegetais. Sessão I. Bancos Ativos de Germoplasma. CENARGEN-EMBRAPA, Brasilia. 210p.

(Aceito para publicação em 25/11/82) 